STRUCTURAL ANAYSIS OF THE CENIRAI TRACKING CHAMBER

Mark Ieininger

July 23, 1982

\begin{abstract}
ANSYS has been used to determine the deflection of the central tracking chamber and stress levels during construction and in the final configuration.
\end{abstract}

\title{
Introduction
}

The central tracking chamber (Fig. 1) is made of two aluminum dished heads 108 in. in diameter separated by a distance of approximately 10 feet. Approximately 40,000 wires are strung between the heads, each wire requiring a 0.120 in. diameter hole penetrating the head. There must be sufficient tension in each wire to prevent excessive sag. The questions to be answered are:

1. In the final assembled state, what will be the deflection of the head both radially and axially (need to know wire positions).

2. How large an effect do the edge conditions of the dished head have on the final deflection; i.e., how does one support the dished head.

3. How does the head deform during assembly.

4. What are the stress levels in the head. 
Fig. 1

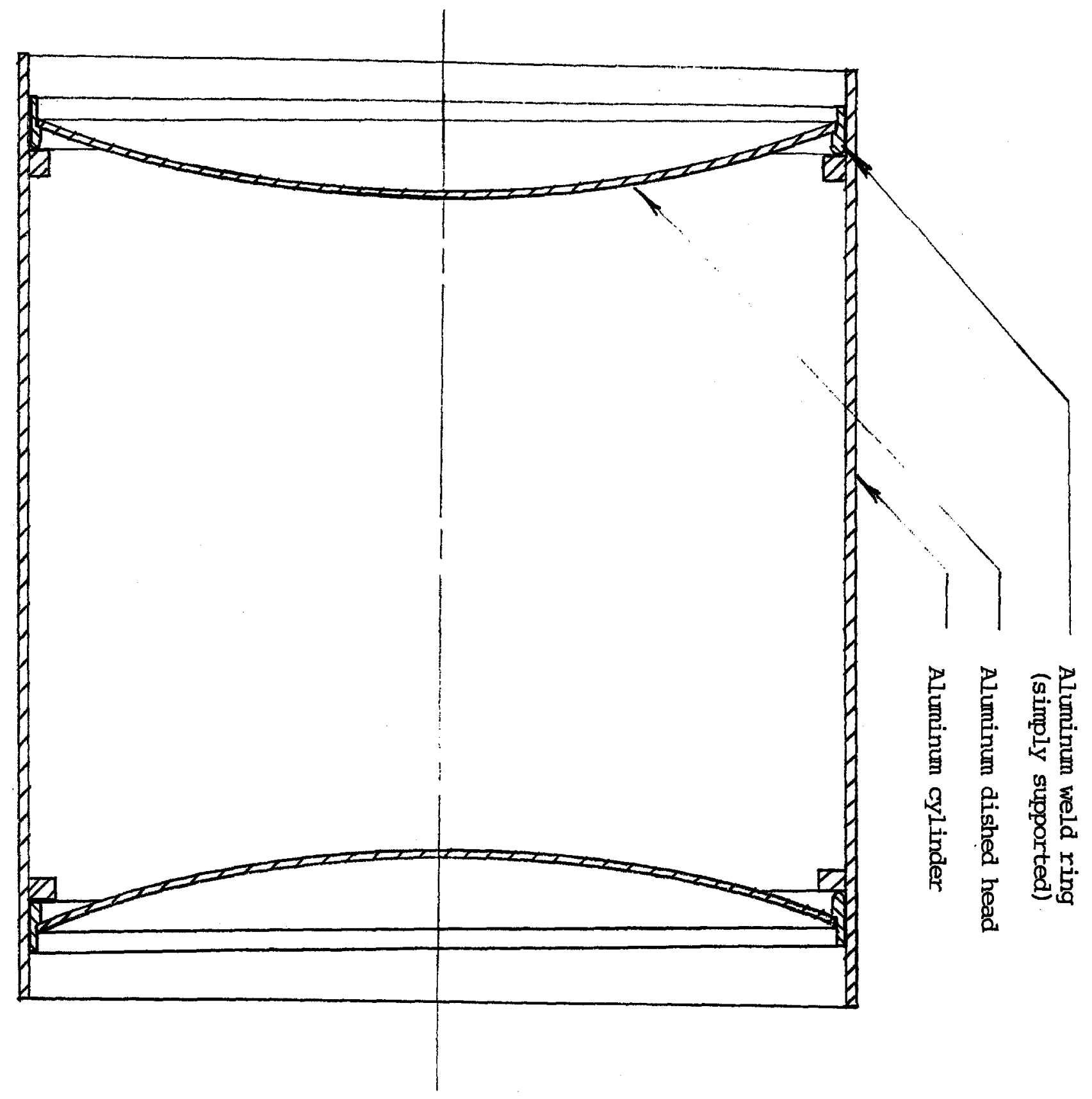




\section{Validation of Results}

There is no way to accurately predict the deflection of a dished head by analytical methods. For this reason, ANSYS, a finite element program, has been used. Before tackling the problem at hand, one needs to establish the validity and accuracy of the finite element method for a problem of this type. By considering a flat circular plate with a hole in the middle of the same size as the dished head, one can compare the ANSYS solution with an analytic solution. Fig. 2 shows such a plate. First, using Roark, Page 339, Case $2 \mathrm{a}$ (simple support), the following results are obtained.

Fig. 2

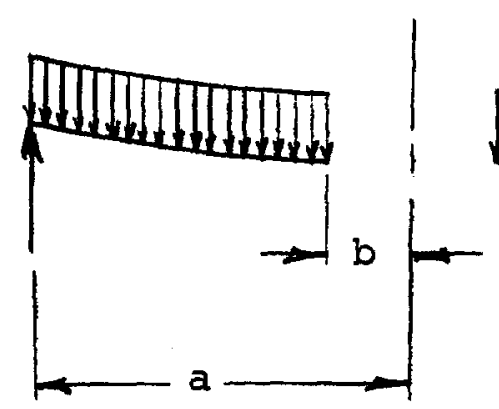

$c_{1}=1.2602$

$\mathrm{C}_{7}=2.7817$

$I_{11}=0.0112$

$I_{17}=0.1848$

$D=(4.5 \mathrm{E} 6)(.375)^{3} / 12\left(1-.3^{2}\right)=2.173 \mathrm{E} 4$

$\mathrm{K}_{\mathrm{yb}}=0.0725$

Resulting in a deflection at the inner hole:

$$
y_{b}=k_{y b} \frac{g a^{4}}{D}=-2.91 \text { in. }
$$


Fig. 3

STEP $=1$ ITER $=1$ TIME $=0$

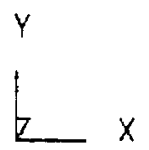


The ANSYS solution for the same loading is -2.93 in., a difference of about 0.7 percent. The distorted geametry plot for the circular plate is shown in Fig. 3. It is of further interest to note that the same flat circular plate with a fixed edge deflects approximately .645 in. One should, therefore, expect large differences in deflection based on different edge conditions. The second case used to compare ANSYS with an analytical solution is a partial distributed load over the same flat plate. The significance of this case will be abvious in later sections of this paper. The problem to be solved analytically is shown below:

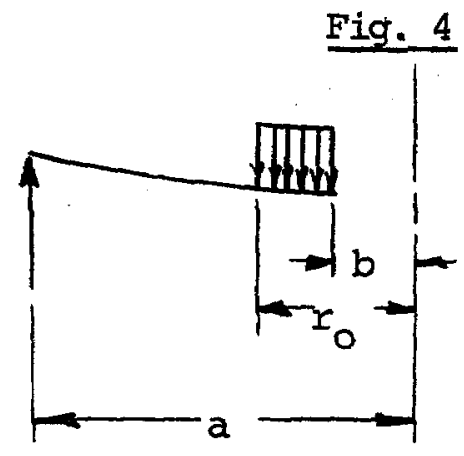

$$
\begin{aligned}
& a=54.331 \mathrm{in} . \\
& b=8.661 \mathrm{in} . \\
& r_{0}=17.795 \mathrm{in} . \\
& q=0.1 \mathrm{psi} \\
& E=4.5 \mathrm{E} 6 \mathrm{in} . \\
& t=0.375 \mathrm{in} . \\
& v=0.3
\end{aligned}
$$$$
\text { WIIJ }
$$

Roark, Page 339, Case 2a, has the load applied as shown below, so superposition must be used to solve the case just described.

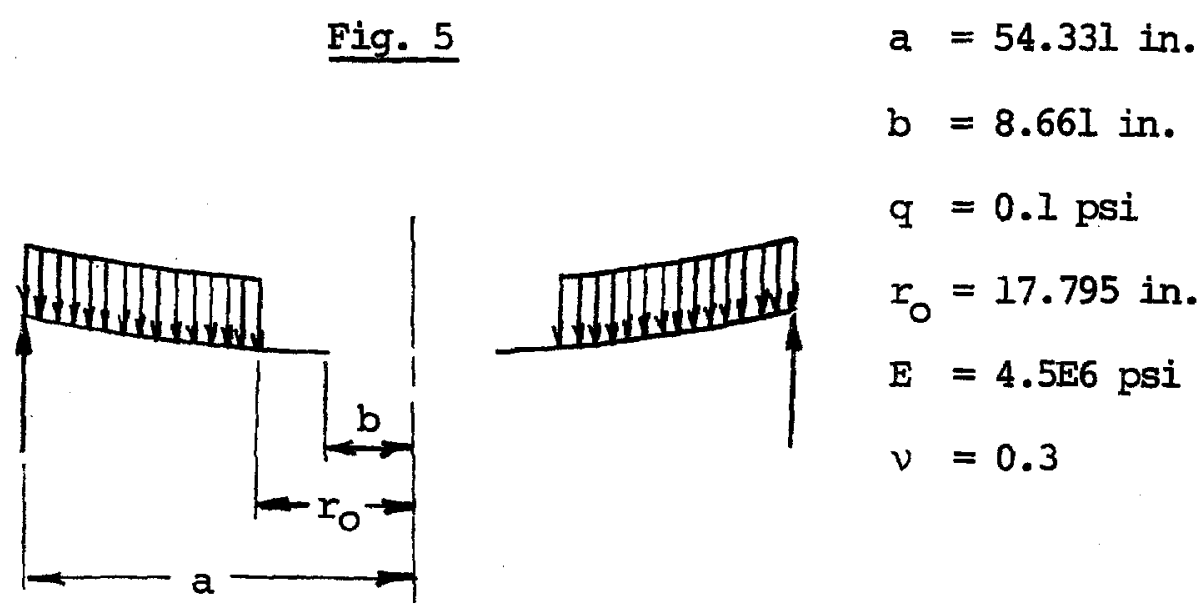




$$
\begin{aligned}
& C_{1}=\left(\frac{1+0.3}{2}\right)\left(\frac{b}{a}\right) \ln \left(\frac{a}{b}\right)+\left(\frac{1-v}{4}\right)\left(\frac{a}{b}-\frac{b}{a}\right)=1.2602 \\
& C_{7}=\frac{1}{2}\left(I-.3^{2}\right)\left(\frac{a}{b}-\frac{b}{a}\right)=2.7817 \\
& \left.I_{11}=\frac{1}{64}\left(1+4{\frac{r_{0}}{a}}^{2}-5\left(\frac{r_{0}}{a}\right)^{4}-4\left(\frac{r_{0}}{a}{ }^{2}, 2+\frac{r_{0}}{a}\right)^{2}\right) \ln \frac{a}{r_{0}}\right)=0.00566 \\
& L_{17}=\frac{1}{4}\left(1-\left(\frac{1-.3}{4}\right)\left(1-\left(\frac{r_{0}}{a}\right)^{4}\right)-\left(\frac{r_{0}}{a}\right)^{2}\left(1+(1+.3) \ln \left(\frac{a}{r_{0}}\right)\right)=0.1410\right. \\
& \text { D } \quad=2.173 E 4 \text { (see Eq. I) } \\
& \left.Y_{D}=\frac{(-0.1)(54.331)}{2.173 E 4} \frac{(1.2602)(0.1410)}{2.7817}-0.00566\right)=-2.33
\end{aligned}
$$

The solution for the case of interest (Fig. 4) is found by subtracting Eq. 3 from Eq. 2:

$\mathrm{Y}_{\mathrm{b}}=-2.91+2.33=-0.58 \mathrm{in}$.

The ANSYS solution for this case is -0.574 in. The distorted geametry plot for this case is shown in Fig. 6.

One last point which needs to be mentioned concerning validation of results is that the cases solved so far have involved pressure loading in which the loading stays normal to the surface of the plate. For flat plates and small deflections applying pressure loads is an accurate way of modeling the Ioads applied by wires which always pull in the axial direction. However, for dished heads, the surface of the plate is not normal to the force applied by the wires, consequently one must use a mass type loading in which the plate material is assigned in artifically high density to model the force of the wires. A sketch may make this more clear: 
Fig. 6

STEP $=1$ ITER $=1$ TIME $=0$




Pressure Load

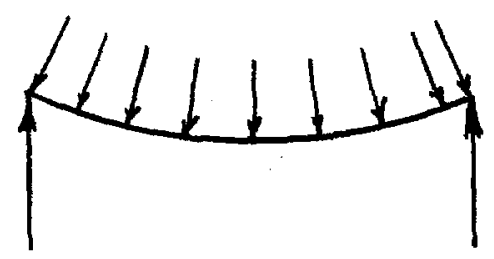

Mass Ioad

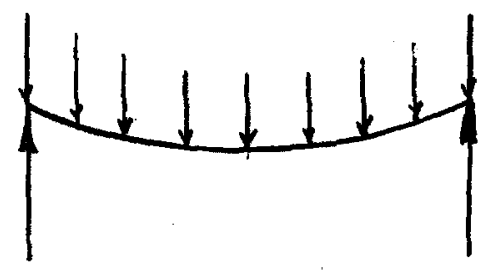

For the purpose of demonstrating the validity of this technique, the two cases solved previously (Fig. 2 and Fig. 4) have been resolved by assigning a density of $.000690 \mathrm{I} \mathrm{lb} \mathrm{s}^{2} / \mathrm{in} .^{3}$ to the flat plate and removing the pressure load of $0.1 \mathrm{psi}$. The density was computed so as to apply the same total force over the surface of the flat plate as a pressure load of 0.1 psi applies. The results of the ANSYS solutions for the two cases are sumarized in Table 1. As a point of interest, the difference between deflections produced by mass and pressure loading applied to a dished head is approximately 30 percent. one clearly cannot use pressure loading to model the real problem. 
Table I

ANSYS Solution

Analytic Solution (Pressure)

Pressure Load

Mass Ioad

$\begin{array}{cc}\text { Full Ioad } & \text { Partial Load } \\ \text { (Fig. 2) } & \text { (Fig. 4) } \\ -2.91 & -0.58\end{array}$

$\begin{array}{cc}\text { Full Load } & \text { Partial Load } \\ \text { (Fig. 2) } & \text { (Fig. 4) } \\ -2.93 & -0.57\end{array}$

Full Ioad

(Fig. 2)

Partial Ioad

$-2.93$

$-2.93$

(Fig. 4)

$-.058$ 


\section{Elastic Constants}

The dished head has a 0.120 in. diameter hole for each wire to penetrate through. There will be approximately 40,000 holes in each head. One must, therefore, modify the elastic constants for the head by an appropriate amount. Robert cook at the University of Wisconsin brought to our attention a paper by Slot and O'Donnel which describes a fairly simple way to treat perforated plates. Although the wire pattern is not exactly uniformly distributed over the dished" head, it is close enough to allow modeling the load as a uniform pressure load of 4.1 psi or a total force on the head of about 35,000 b. The assumption of a uniform hole pattern also allows the elastic constants to be detemined as described in Slot's paper. All effective elastic constants will be denoted with an asterisk. The material used is aluminum. Compute $E^{*}$ using Slot and O'Donnell's paper:

$$
\begin{aligned}
& 2 p \cos 30+p=.5669 \\
& p=\frac{.5669}{2 \cos 30+I}=0.20750 \\
& \begin{aligned}
h & =p-\text { dia }=0.20750-.120 \\
& =0.08750
\end{aligned}
\end{aligned}
$$

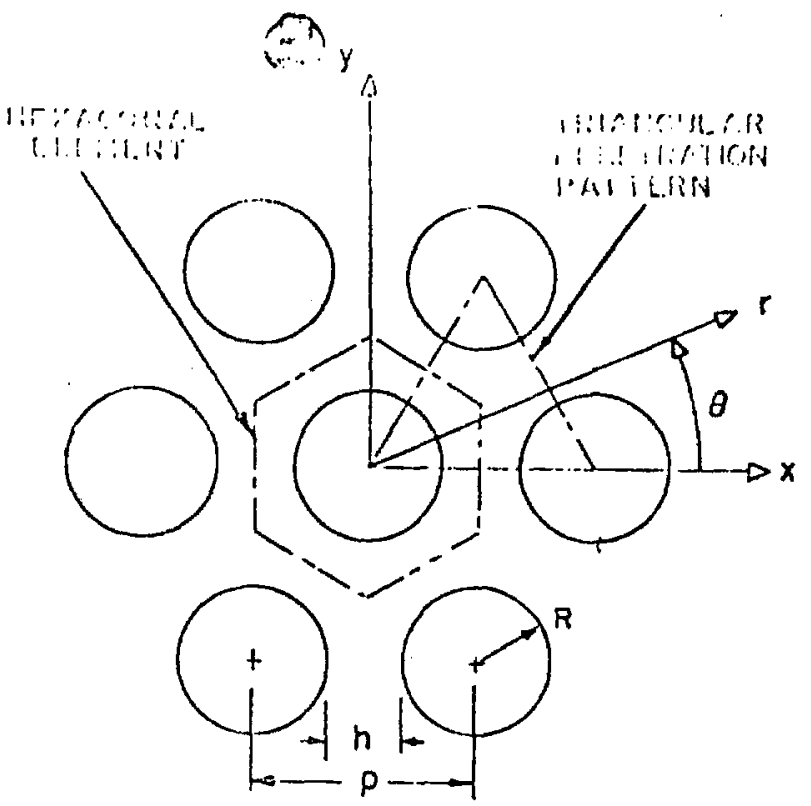


Ligament efficiency $n=\frac{h}{p}=\frac{.0875}{.2075}=0.422$. From Table 4:

$\frac{E^{*}}{E}=.3105+\left(\frac{.422-.333}{.5-.333}\right)(.5291-.3105)=.4270$

$v=.3400$

$\frac{\mathrm{G}^{*}}{\mathrm{G}}=.4161$

$E^{*}=(.4270)(10.6 \mathrm{E} 6)=4.526 \mathrm{E} 5 \mathrm{psi}$

$\nu^{*}=.3400$

$\mathrm{G}^{*}=(.4161)(4 \mathrm{E} 6)=1.66 \mathrm{E} 6 \mathrm{psi}$ 


\section{Eirst Approximation to Solution}

To establish the upper and lower limits of deflection within which all proposed construction techniques will fall, the dished head will first be treated as a simplified dished head with no flange, 108 in. outer diameter, $17.324 \mathrm{in.}$ diameter center hole, $0.375 \mathrm{in.}$ thickness, and aluminum material with the effective elastic constants described in the previous section. This simplified head will be simply supported and fixed at the outer diameter. The actual dished head will have a stiffening ring welded around the outer diameter and will probably approach the fixed edge case rather closely. The simplified head is shown in Fig. 7. The simply supported head under a load of 4.1 psi is shown in the deflected position in Fig. 8. The maximm displacement in the $\mathrm{Y}$ direction (at the edge of the hole) is 0.251 in. The maximm radial displacement (at the outer edge) is 0.120 in.

The fixed edge head is shown in the deflected position in Fig. 9. The maximm displacement in the $\mathrm{Y}$ direction is $0.013 \mathrm{in}$. The maximum radial displacement (at $r=35$ in.) is approximately .003 in. These two cases establish the window within which all actual construction cases will fall. 
Fig. 7

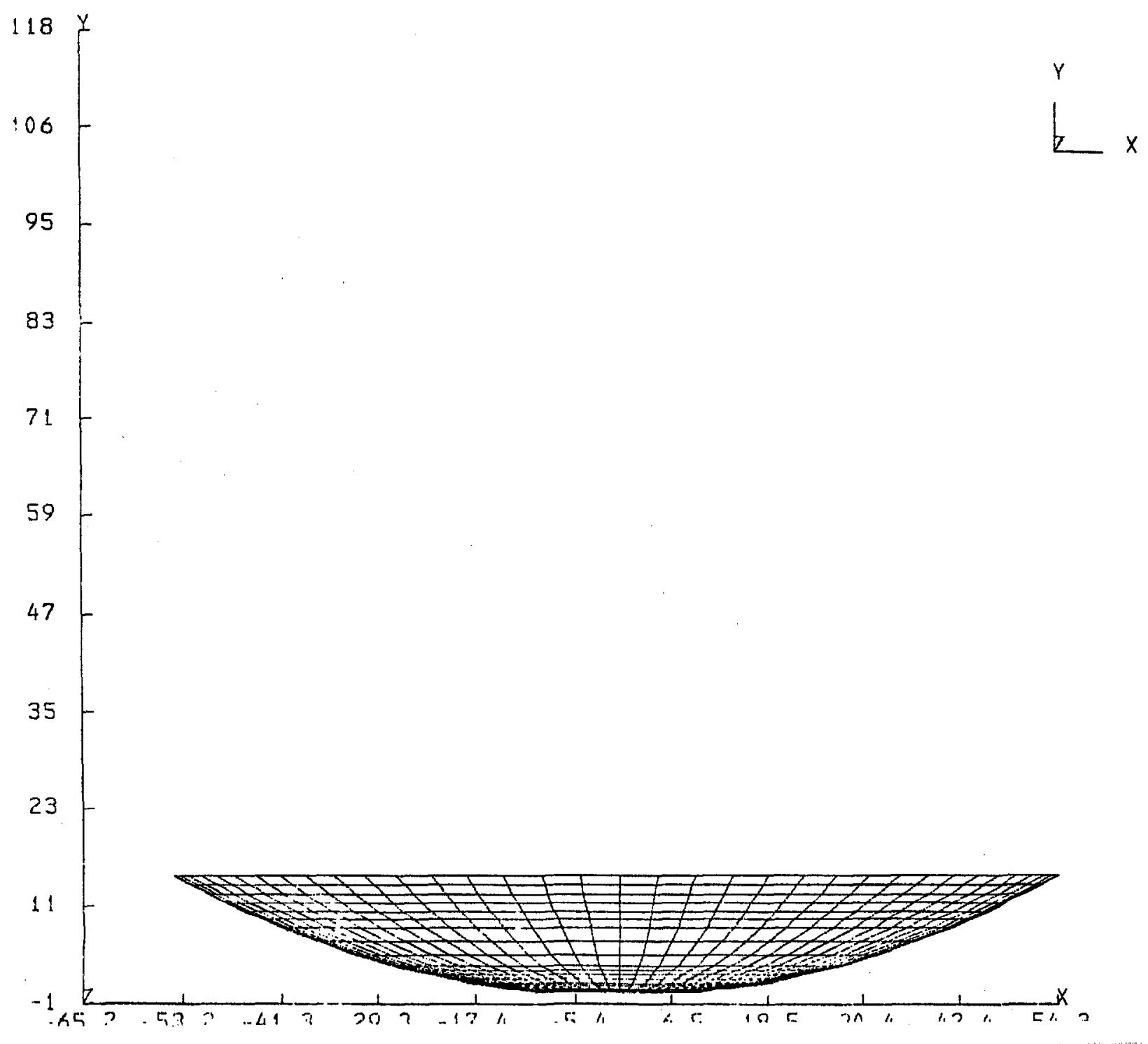


Fig. 8

STEP $=1$ ITER $=1$ TIME $=0$ .25134
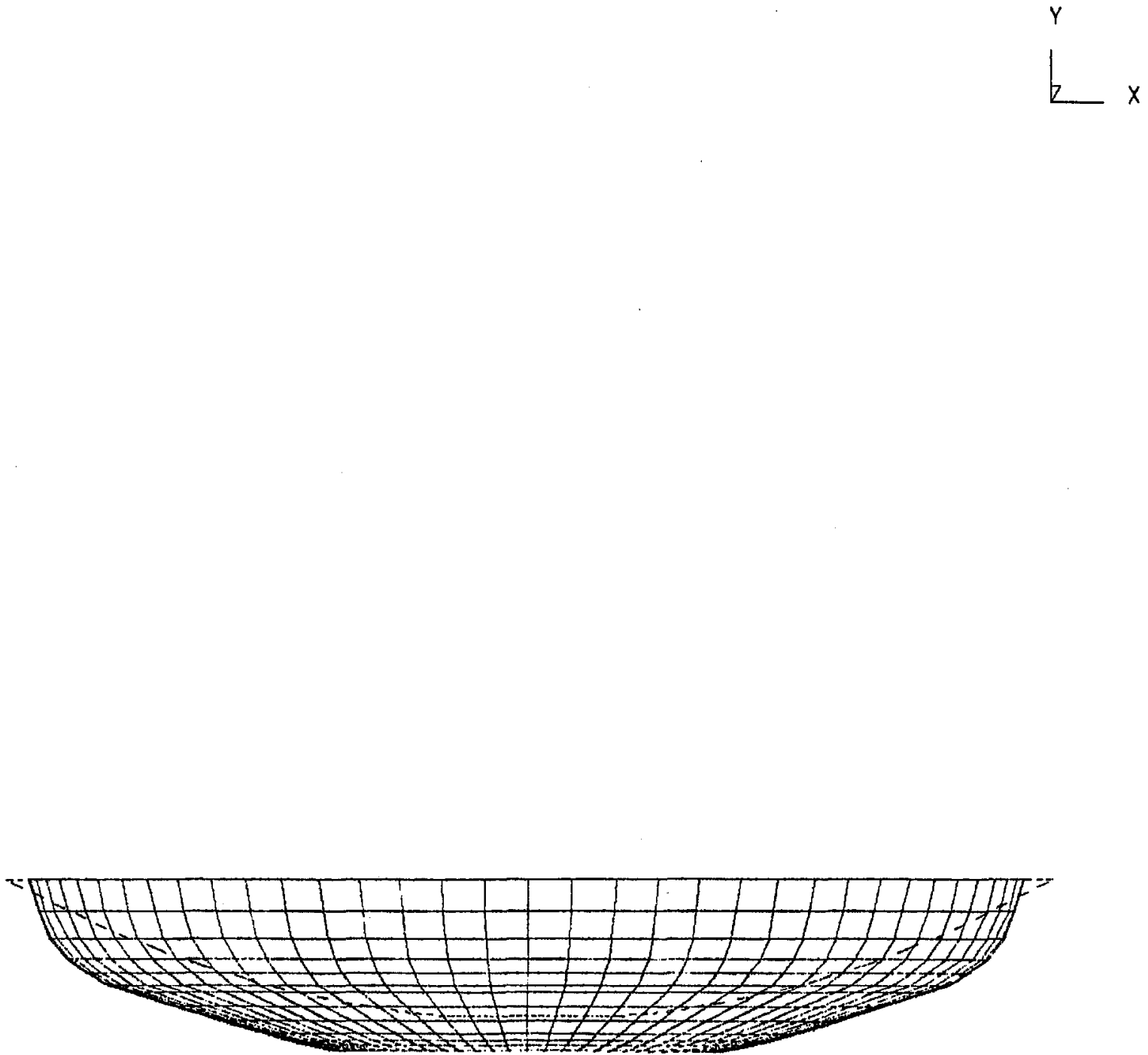
$-15-$

Fig. 9

STEP $=1$ ITEA $=1$ TIME $=0$

.01271

r $x$

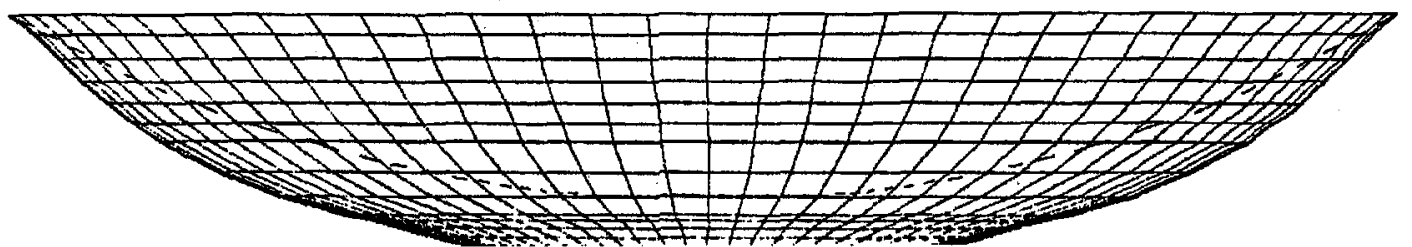




\section{Solution with Outer Stiffening Ring}

The actual dished head is shown in Fig. 10. Note that there is an aluminum stiffening ring welded around the circumference of the same dished head treated in the previous section. The head will be supported by simply supporting the stiffening ring as shown. The stiffening ring is 4 in. wide and I in. thick.

Not only is the final deflected state of interest but the behavior of the heads during stringing of the wires is of interest to help determine whether each wire should be tensioned as strung (using little springs at the end of the wire) or whether all wires should be strung loosely and the entire assembly post tensioned by driving the heads apart. Because the assembly technique is still unclear, the effects of gravity should be considered on the head when it is oriented with its axis parallel to the ground. If the effects of gravity tending to distort the head into an ellipse are small, the analysis can be done ignoring gravity and including only the effects of the wires. Fig. 11 shows the distorted shape of the head due to its own weight when standing on edge. The maximum deflection is just less than .001 in., so gravity will be ignored.

The actual assembly sequence will be modeled by applying the load in annuli of increasing radius, progressing through $180^{\circ}$ at a time. A sketch showing this loading sequence follows:


Third $180^{\circ}$

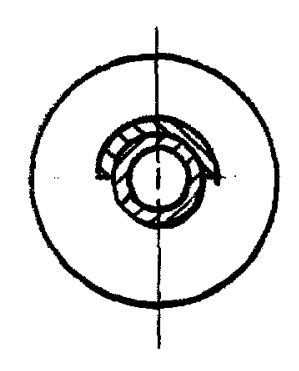


Fig. 10
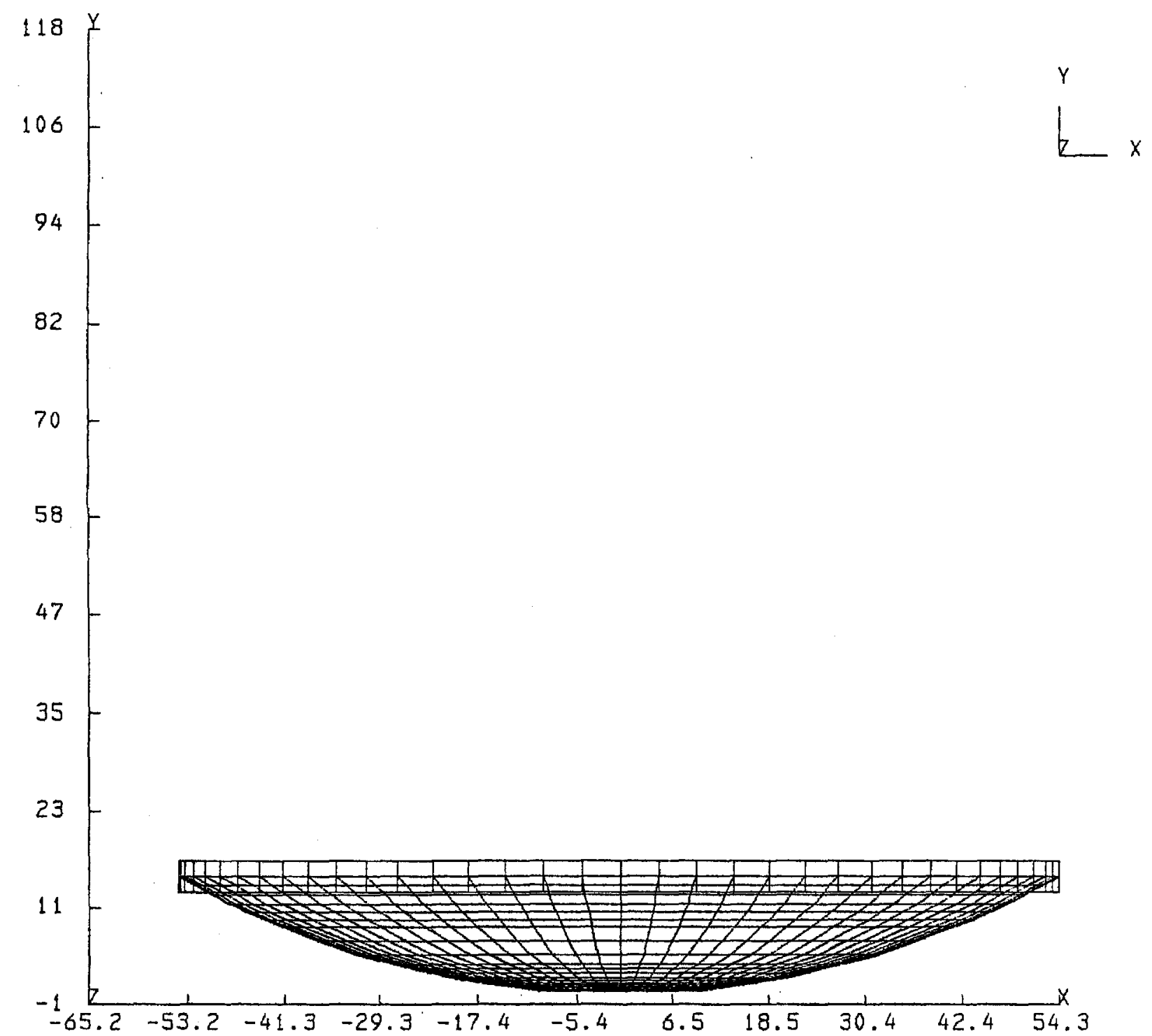

CENTAAL TRACKING CHAMBER. OUTER STIFFENING RING. SIMPLE SUPPORT. GEOMETRRNSYS 
Fig. 11

STEP $=1$ ITER $=1$ TIME $=0$ .00098

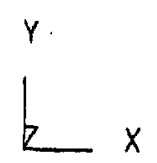

Gravity

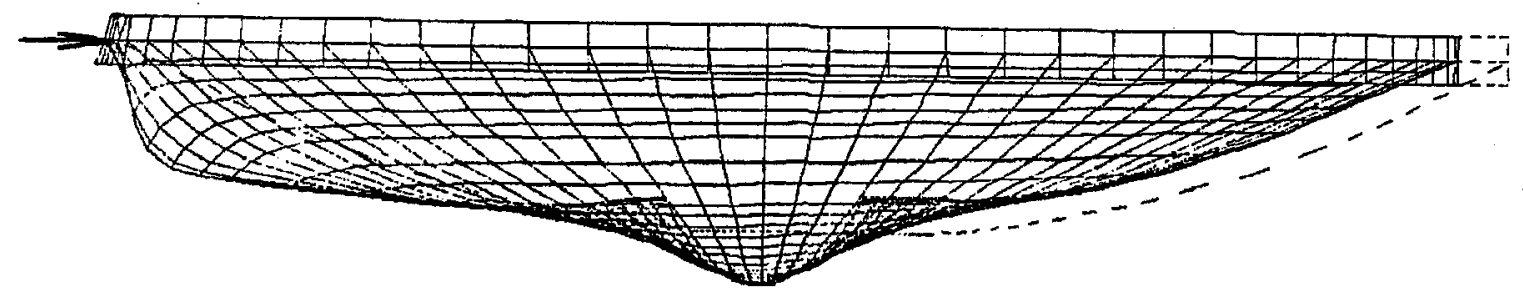


To aid the reader in interpreting the plots (Figs. 12-21) showing the distorted shapes of the head at various stages of winding, note that the plots are made by viewing the head at section $A-A$ labeled in the previous sketch. Actually, only half the head has been modeled. Fig. 10 shows the undistorted shape of the head. Fig. 12 shows the distortion due to application of load in the first $180^{\circ}$ region. The title on this plot (Fig. 12), "EIYPE 1 ON," means that all the element types 1 have had their density turned on so that the load is applied through the first $180^{\circ}$ arc. Fig. 13 shows the distortion due to application of the load in the second $180^{\circ}$ region and is titled "EIYPES 1, 2 oN" to indicate that element types 1 and 2 have had their densities turned on. There are a total of five annuli for a total of 10 element types and, consequently, 10 distorted plots. The number in the upper right hand corner of each plot $(0.03379$ in Fig. 21) indicates the maximum displacement for that particular load case. The maximm displacement in all cases occurs either right at the edge of the inner hole in the head or very near the inner edge. The surprising result is that the maximm deflection is almost reached after the first full annulus is turned on (Fig. 13). Then the displacement decreases as the next annulus is loaded (Fig. 15), increasing smoothly with load to final fully loaded condition (Fig. 21). This can be understood by examining the rotations of the elements as the first annulus is turned on; however, a rather simple physical explanation can be had by considering the following. ${ }^{2}$ Imagine loosely holding the opposite edges of a piece of paper in each hand so that the paper sags in the middle. Application of a load in the center of the paper causes significant deflection. Now consider application of a load on each side of the center of the paper, near your hands. This load causes 
Fig. 12

STEP $=1$ ITER $=1$ TIME $=0$

$.0316 !$
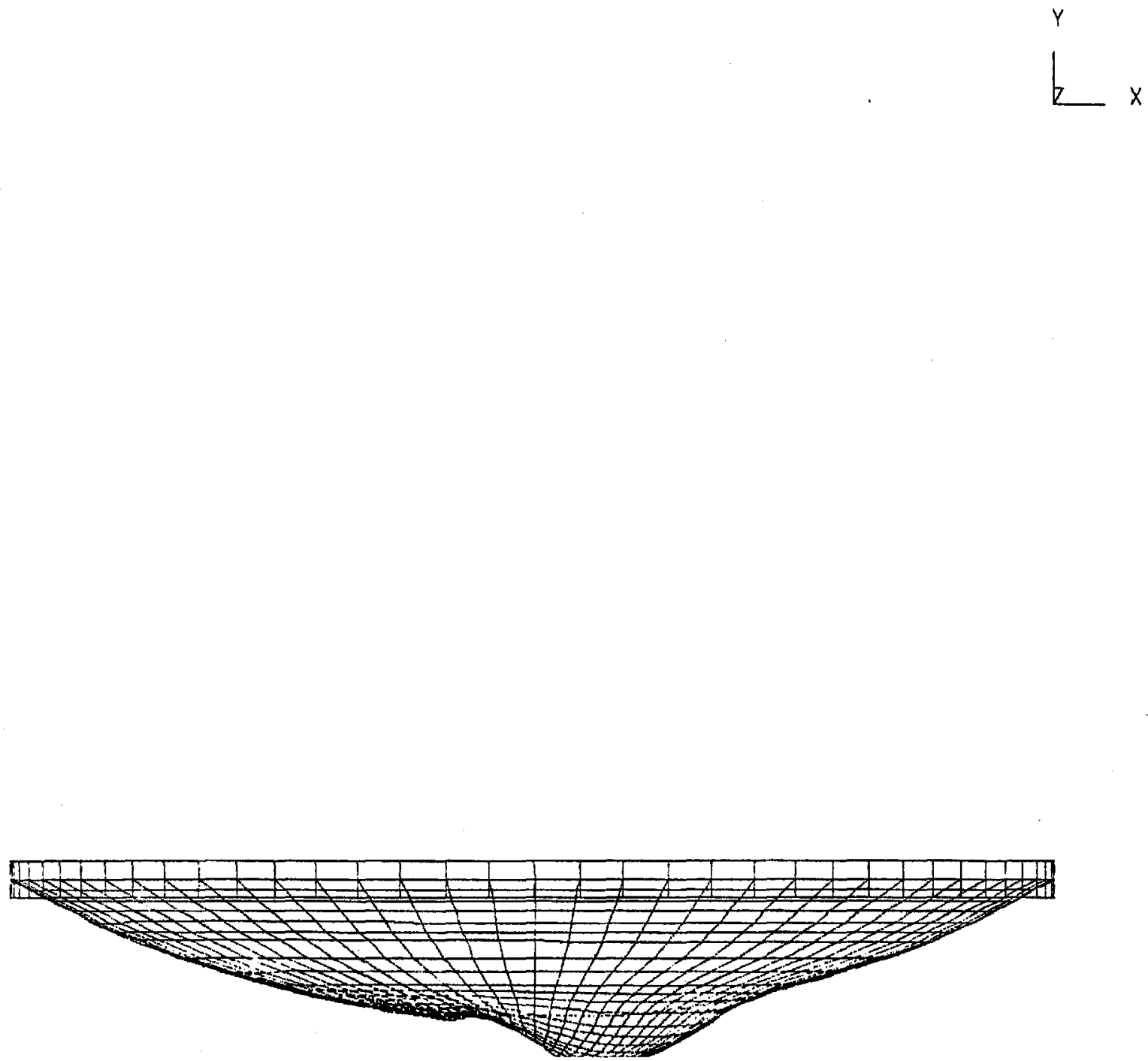
$-21-$

Fig. 13

STEP $=1$ ITER $=: 1$ TIME $=0$

.03264
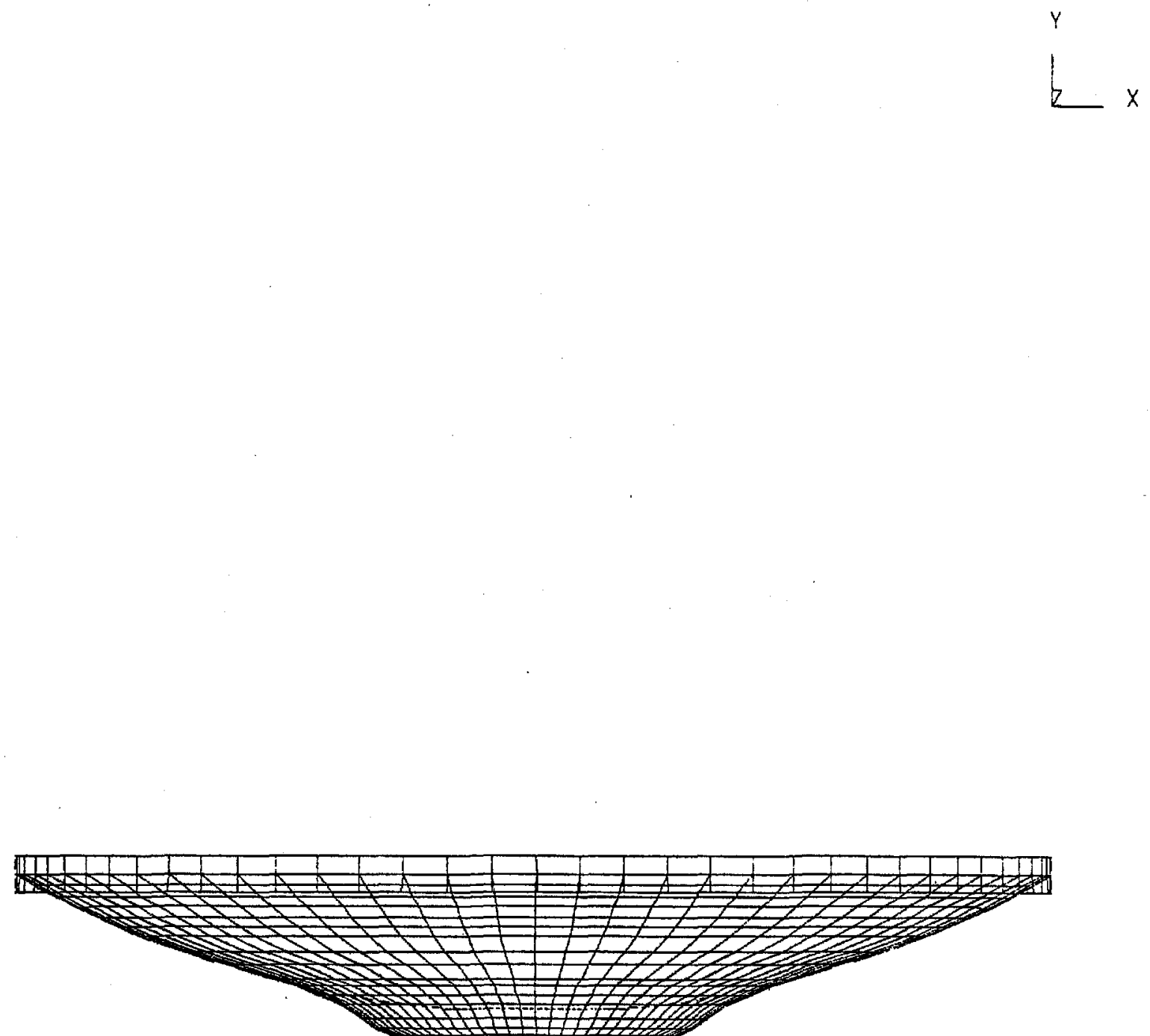
Fig. 14

STEP $=1$ ITER $=1$ TIME $=$

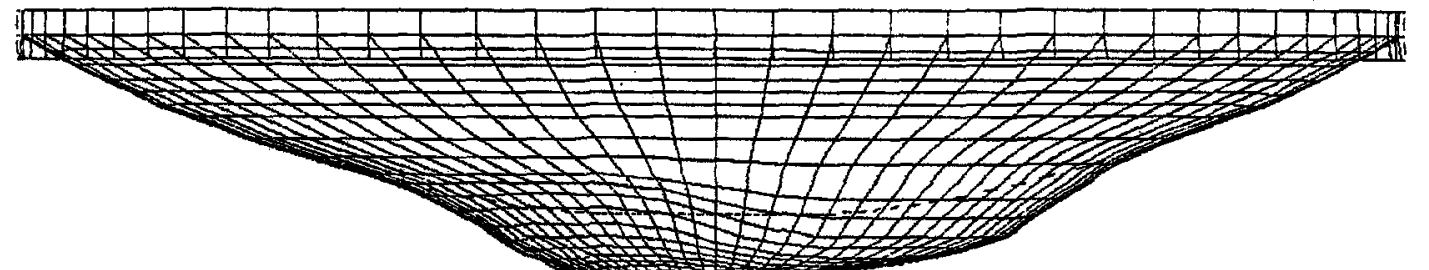


Fig. 15

STEP $=1$ ITER $=:$ TIME $=0$

.02921

Y $\quad X$

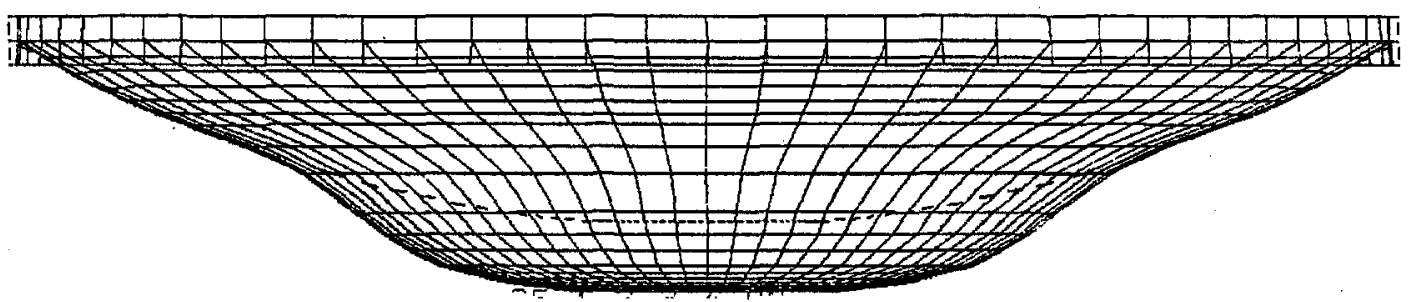


Fig. 16

STEP $=$ 1. ITER $=1$ TIME $=0$

.03034

Y $x$

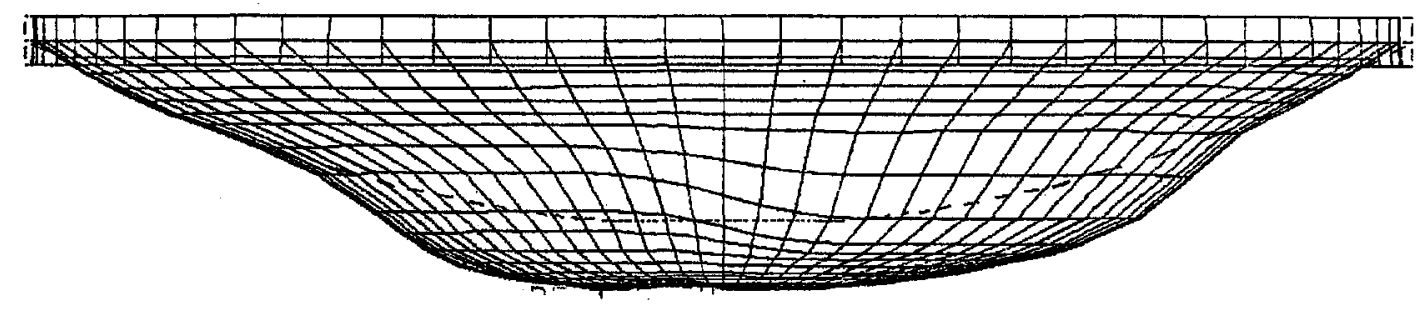


$-25-$

Fig. 17

STEP $=1$ ITEP $=1$ TIME $=0$

.03030
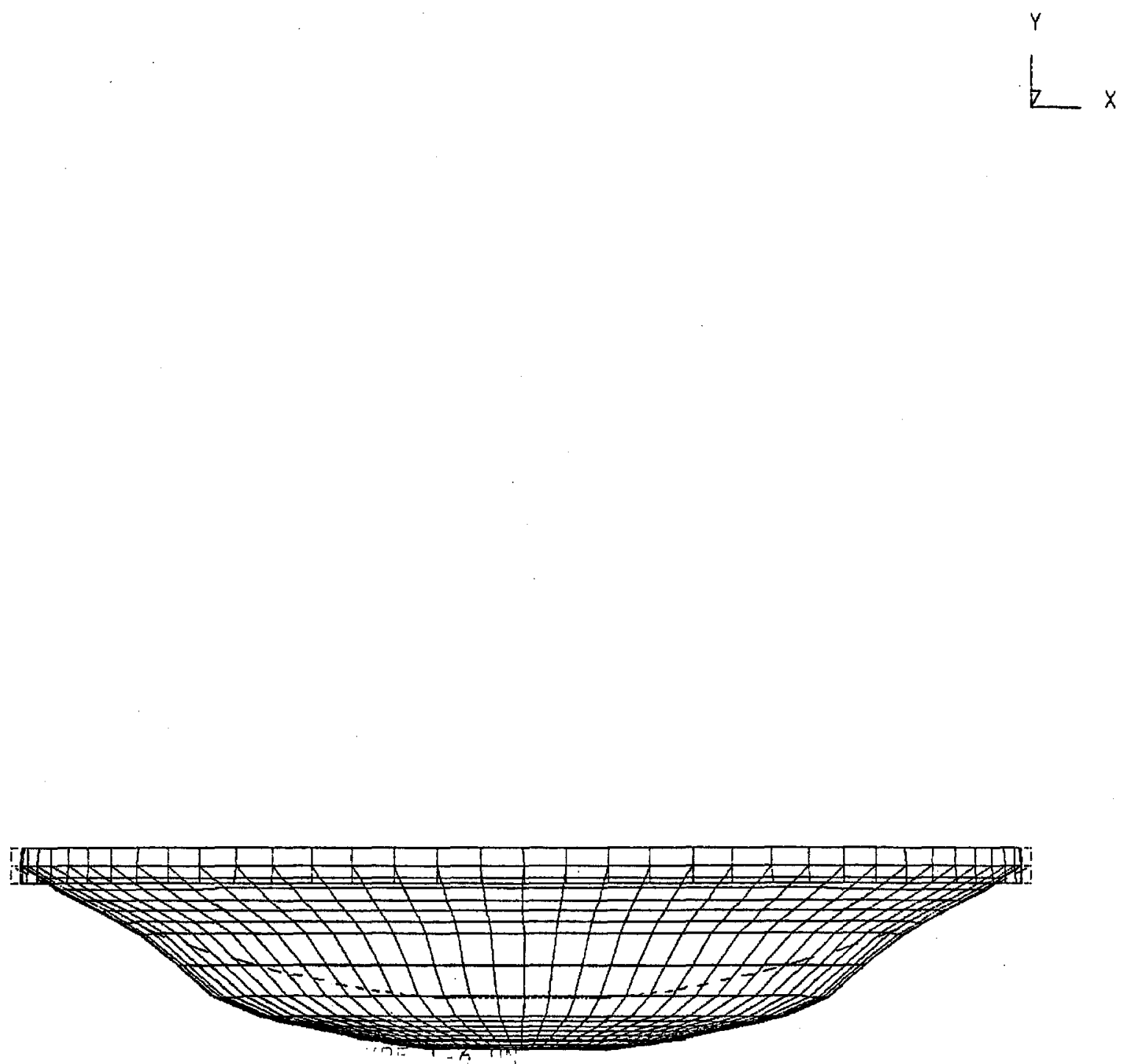
Fig. 18

STEP $=1$ ITER $=1$ TIME $=0$

.03187
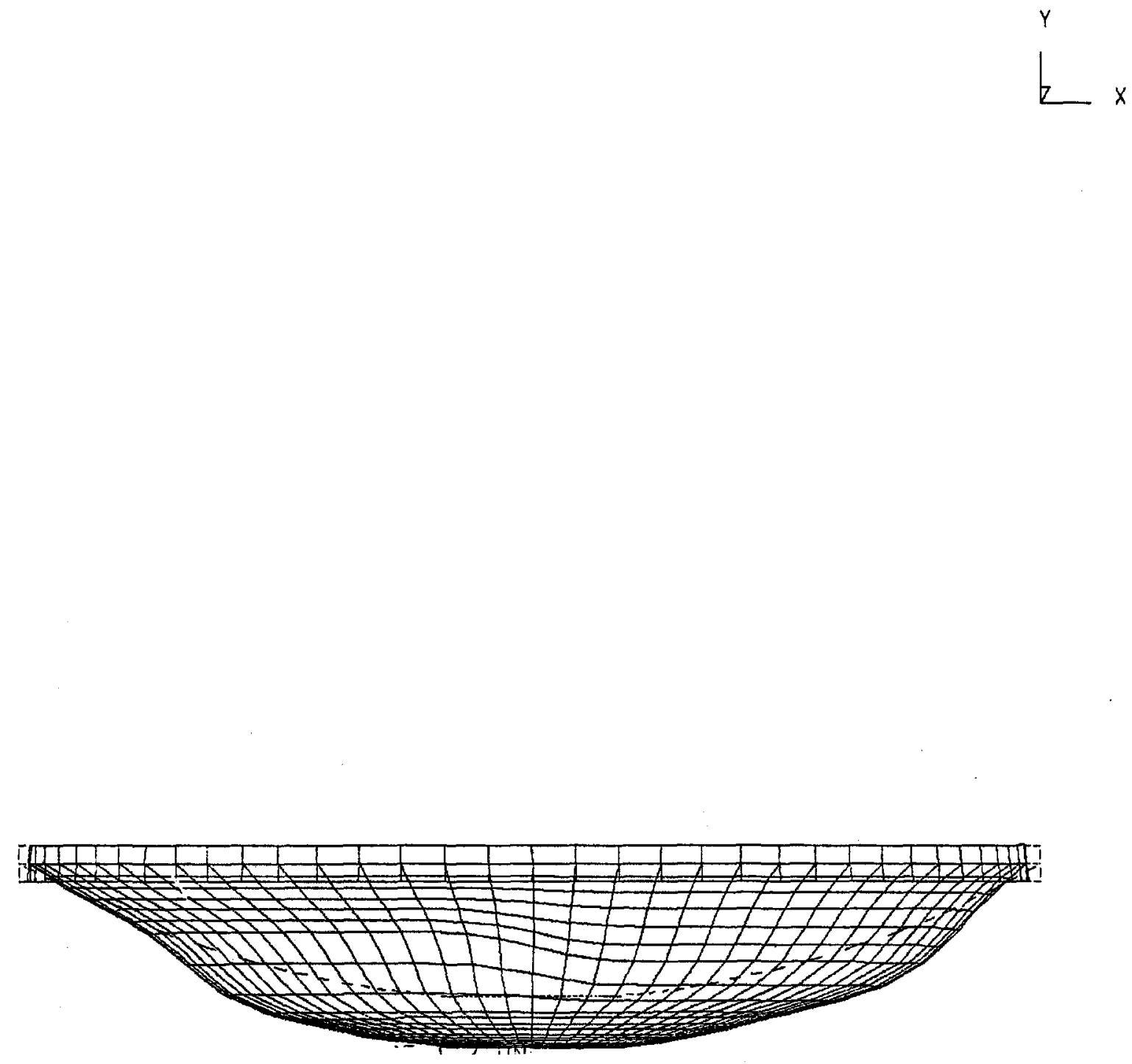
Fig. 20

STEP $=1$ ITER $=1$ TIME $=0$

.03332

Y $x$

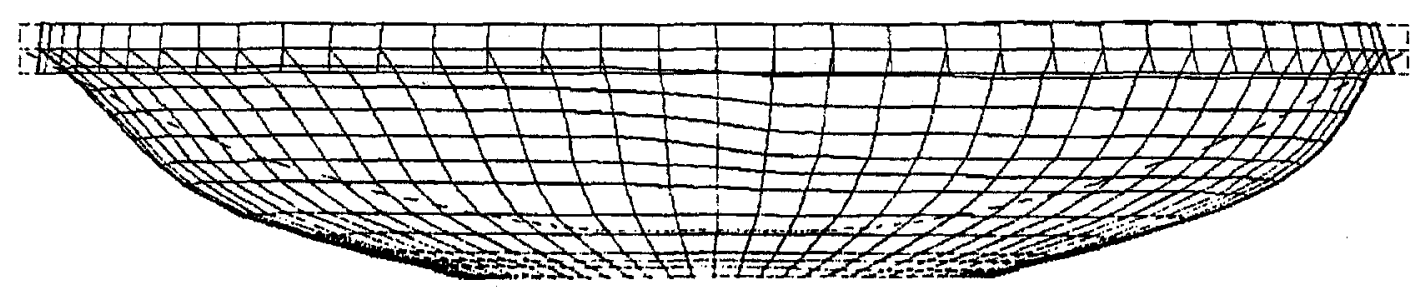


Fig. 21

STEP $=1$ ITER $=1$ TIME $=0$ .03379

$y$
$z$
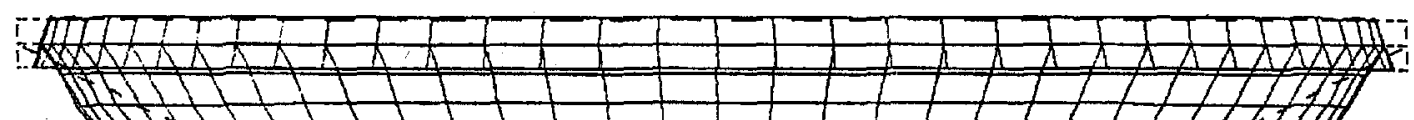

11 
the paper to "balloon" out, and the center of the paper actually deflects up rather than down. A similar effect is seen in the dished head. The final distorted shape (Fig. 21) has a maximm radial displacement at the outer stiffening ring of 0.015 in. and a rotation of the ring of 0.0022 radians.

\section{Solution Using Center Post}

One proposed construction technique involves welding a 1 in. wide by I-I/2 in. thick aluminum ring inside the hole in the dished head, then pulling down on this inner ring until the same maximum deflection is achieved as in the final assembly state (all wires strung). The question to be answered is how closely does the profile of the head match the profile of the head in the final assembly state when pulled down by the inner ring. The answer seen in Fig. 22 is not very close at all. It in interesting, however, to note how closely the first annulus loading (Fig. 13) matches this center post loading (Fig. 22).

\section{Stresses}

Stress concentration factors are needed for perforated plates. Work by O'Donnell and Langer ${ }^{3}$ provides the needed factors. The ligament efficiency already computed (Eq. 5) as 0.422 is used along with Figs. 12 and 13 in the O'Donnell and Ianger paper to determine the following stress concentration factors (SCF) :

$$
\begin{array}{ll}
\text { SCF }=3.3 & \text { for isotropic stress } \\
S C F=5.1 & \text { for uniaxial stress } \\
S C F=2.73 & \text { at the rim }(\rho / b=0.0783)
\end{array}
$$


$-31-$

Fig. 22

STEP $=1$ ITER $=1$ TIME $=0$

.03380

L。

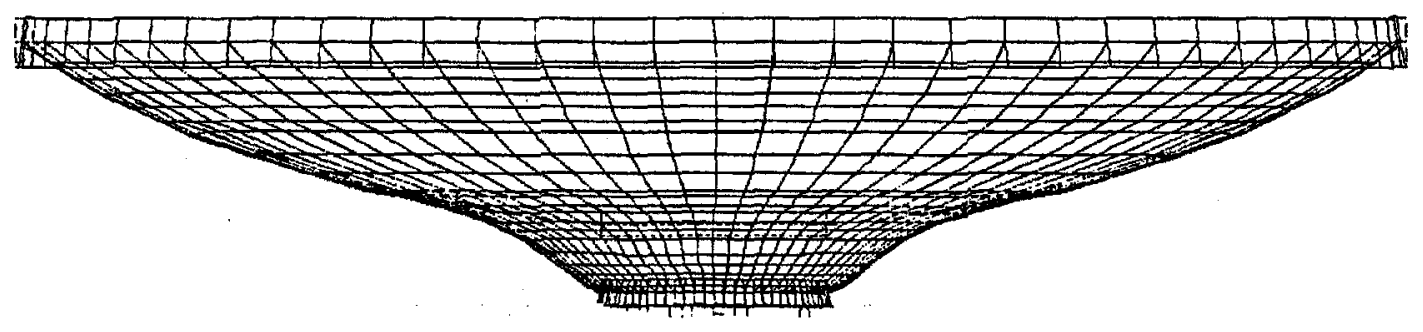


The uniaxial SCF should only be used where either $\sigma_{\text {radial }}$ or $\sigma_{\theta}=0$, i.e. where either radial stress or hoop stress is zero. For the problem at hand, the isotropic SCF is most realistic.

Fig. 23 shows the meaning of the various stress values plotted in Figs. 24 through 31. Fig. 23 shows SMXT, the maximum principal stress on the top surface of the plate element. Both the maximm and minimum values of SMXT are plotted. Note that the convention used throughout is a positive sign for the tensile stresses and a negative sign for compressive stresses. Fig. 25 represents the minimum principal stresses on the top surface. Fig. 26 represents the maximum shear stress on the top surface. Fig. 27 represents the maximum equivalent stress (or Von Mise's stress) on the top surface. Figs. 28 through 31 represent the same stress components on the bottom surface of the plate. The conclusion to be drawn from the stress information comes from the SGET and SGEB plots (Figs. 27 and 31). The maximum value of SGET (2918 psi) occurs in the outer stiffening ring which needs no stress concentration factor applied. The values of SGET near the outer edge of the head are approximately 1500 psi. (This is samewhat difficult to see from the plot but is easily extracted from the printout.) Applying the outer rim SCF of 2.73, the stress levels near the outer rim are on the order of $4500 \mathrm{psi}$, certainly nothing to be concerned about. 
Fig. 23

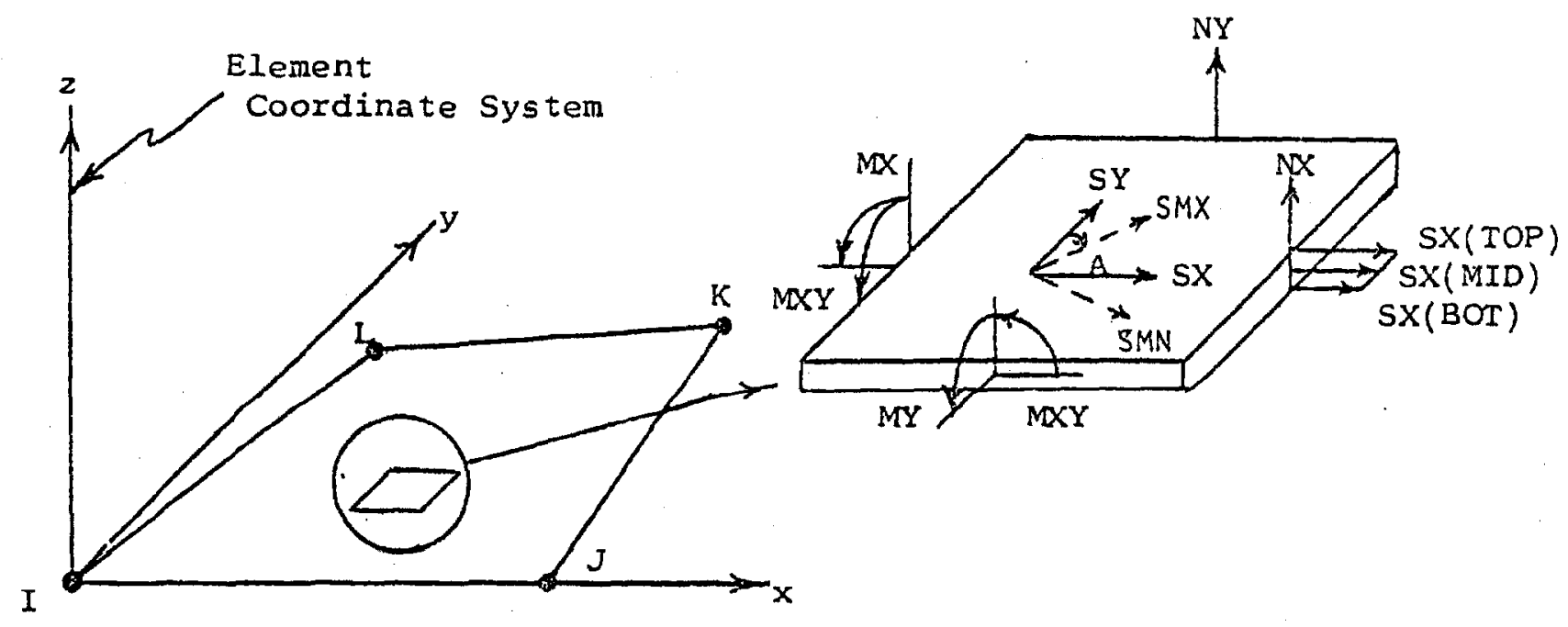

Quadrilateral Shell Output

STIF63 
Fig. 24

STEP $=\quad$ I ITER $=1$ TIME $=0$

80.00

$Y$
1

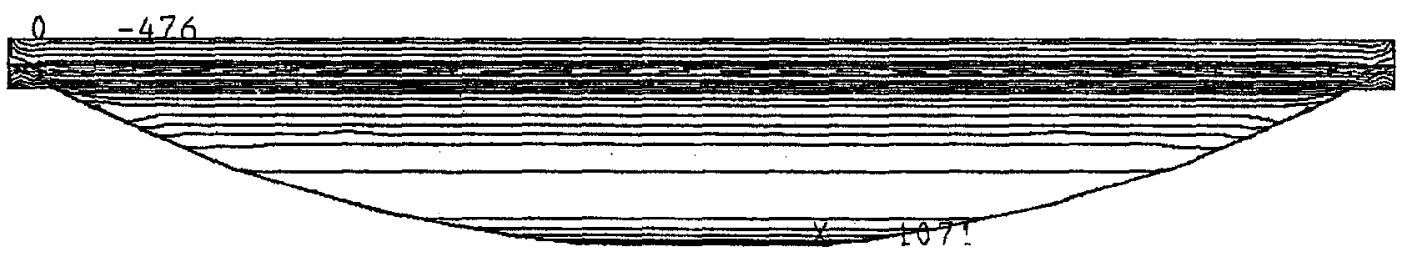


Fig. 25

STEP $=1$ ITER $=$ \& TIME $=0$ 200.00
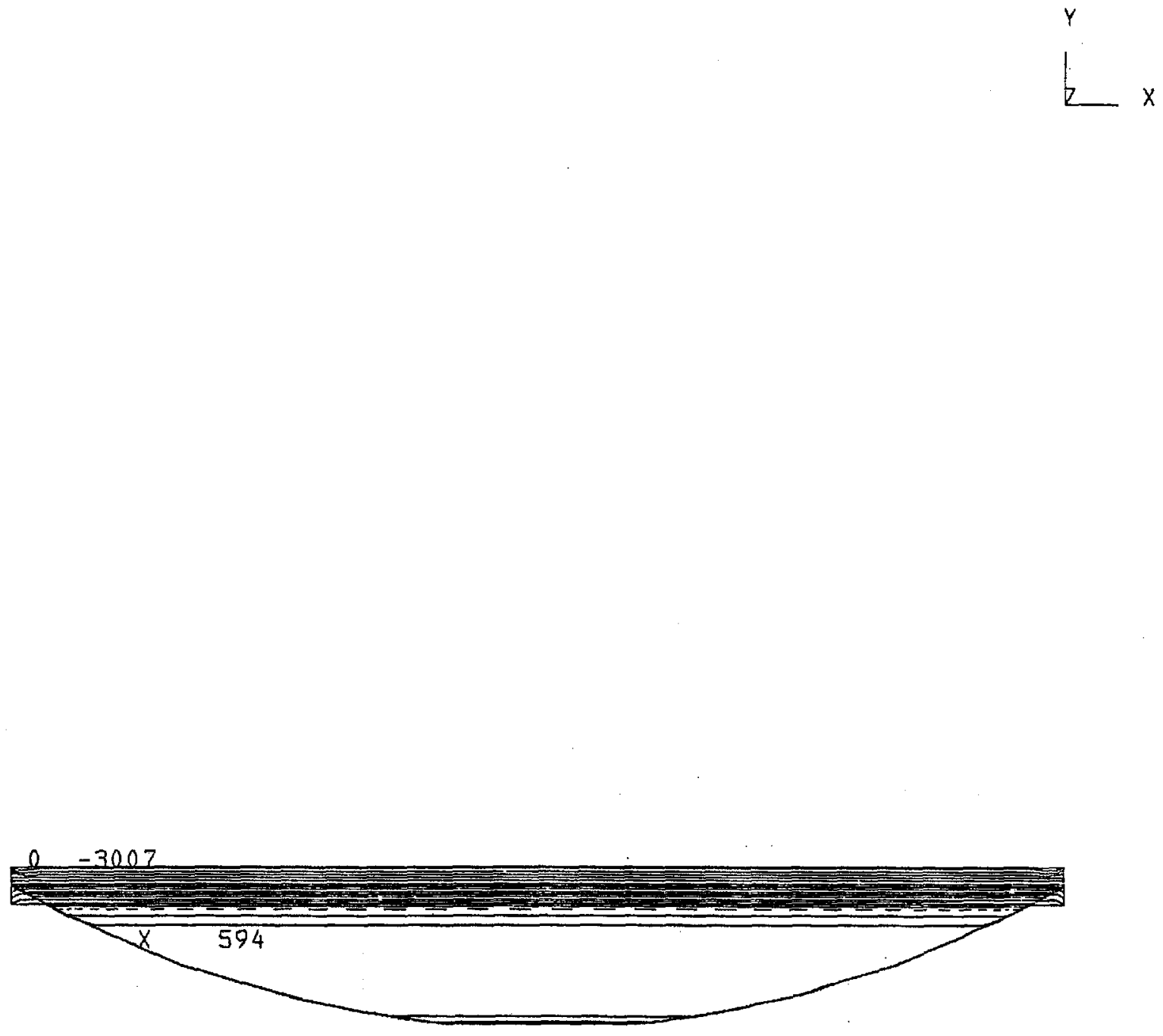
Fig. 26

STEP $=1$ ITER $=1$ TIME $=0$

80.00

Y

$z x$

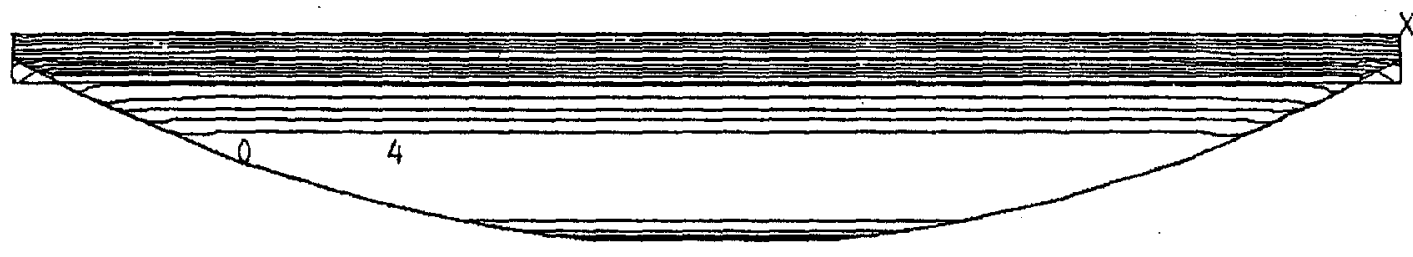

1452 
Fig. 27

STEP $=1$ ITER $=1$ TIME $=0$

150.00
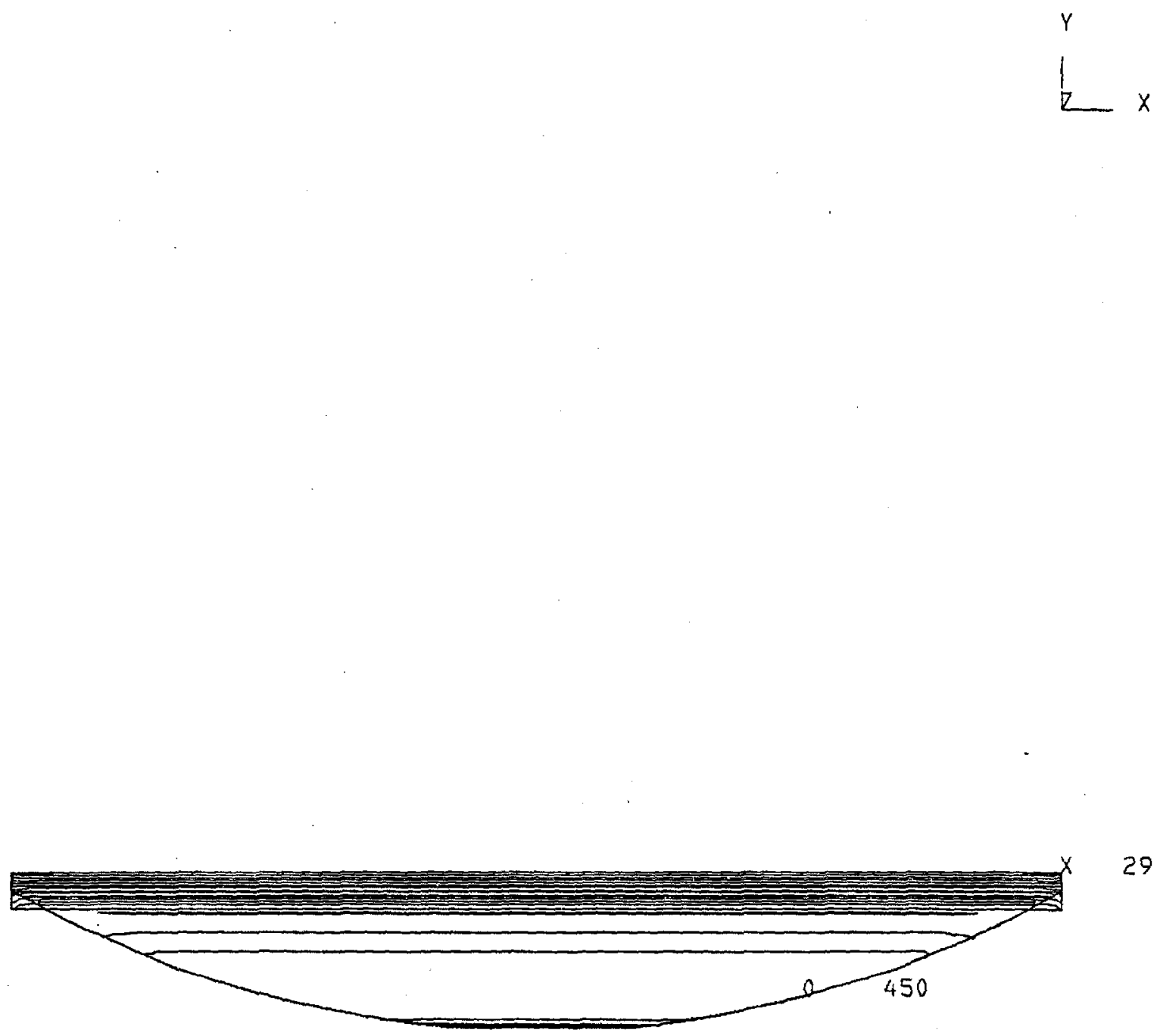

2918 
Fig. 29

STEP $=1$ ITER $=1$ TIME $=0$

200.00
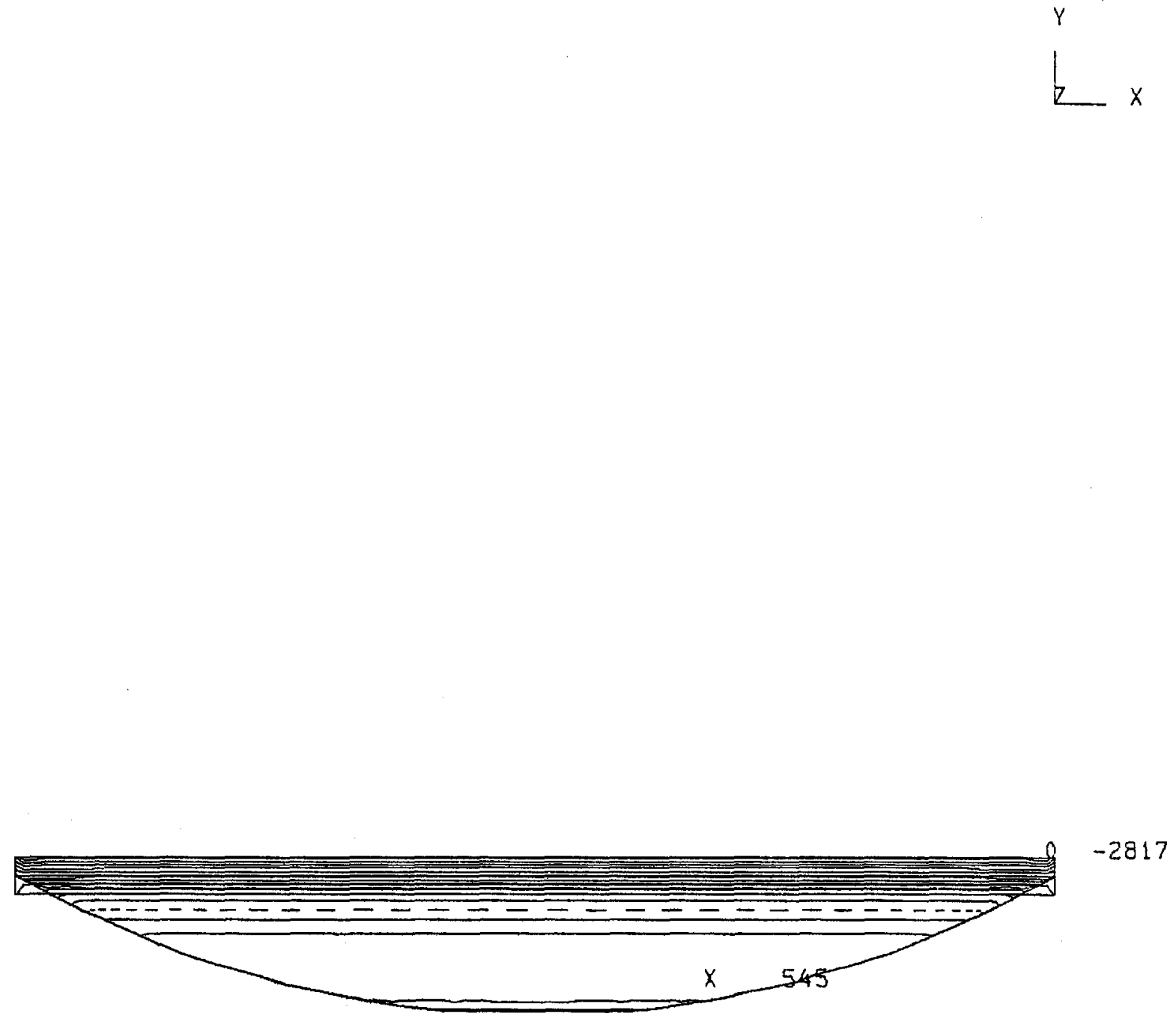
$-40-$

Fig. 30

STEP $=1$ ITER $=1$ TIME $=0$

100.00
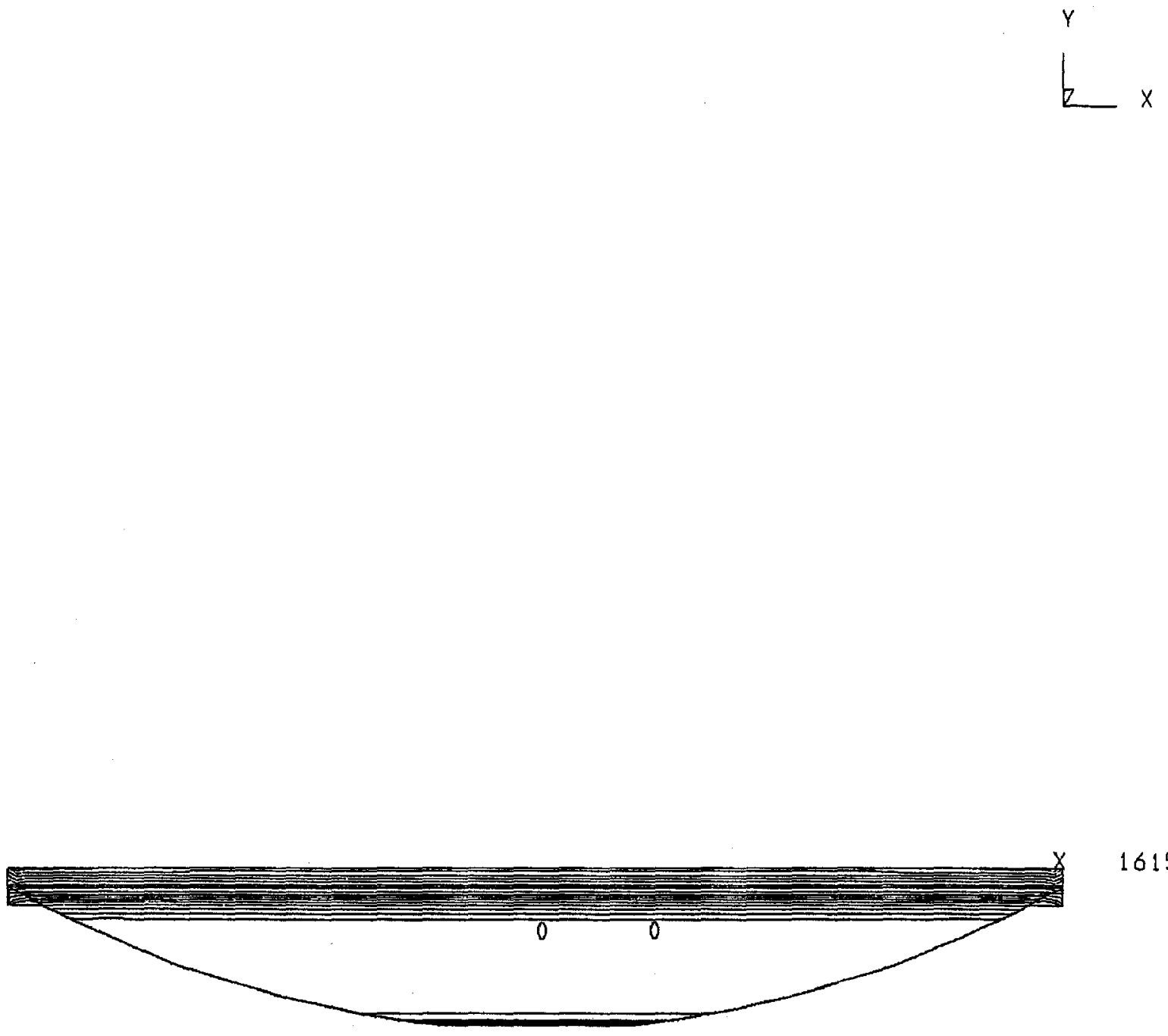

1615 
$-41-$

Fig. 31

STEP $=1$ ITER $=1$ TIME $=0$

200.00
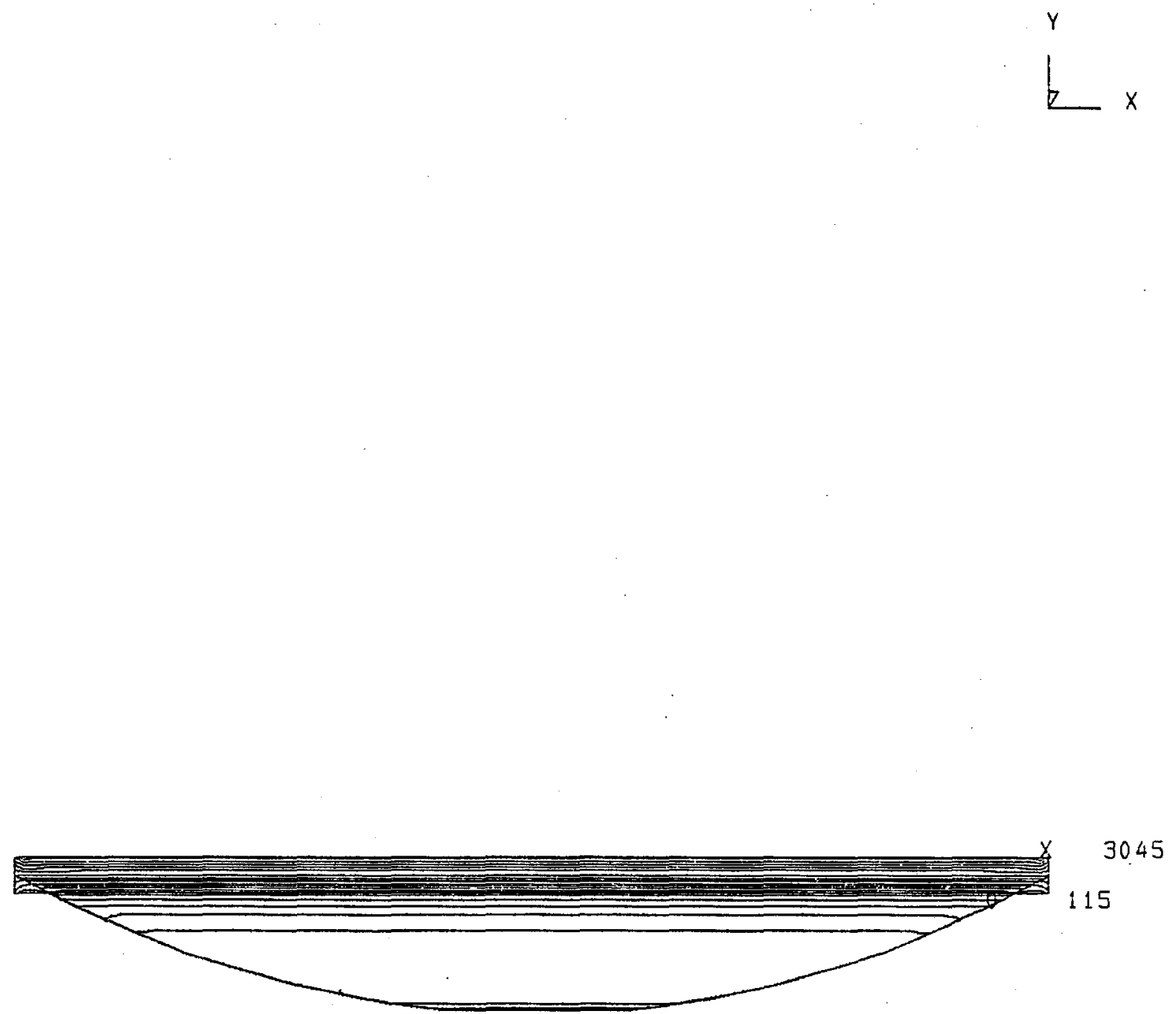


\section{Referrences}

1. Slot and O'Donnell, "Effective Elastic Constants for Thick Perforated Plates with Square and Triangular Penetration Patterns," Journal of Engineering for Industry, November 1971, Pages 935-942.

2. Private conversation with Bab Wands.

3. O'Donnell and Langer, "Design of Perforated Plates," transactions of the ASME, Paper No. 61-WA-115. 